\title{
O trabalho na contemporaneidade e suas implicações na subjetividade dos trabalhadores ${ }^{*}$
}

\author{
Adriana Spilki ${ }^{1}$ \\ Maria da Graça Jacques \\ Miriam Scopel \\ Silvana de Oliveira \\ Universidade Federal do Rio Grande do Sul
}

\section{Resumo}

O objetivo desse ensaio ${ }^{2}$ teórico é o de examinar as transformações em curso no mundo do trabalho e suas implicações na subjetividade dos trabalhadores. A partir de três recortes ilustrativos, analisa-se as implicações daí derivadas que se expressam nos modos de viver e de adoecer dos trabalhadores. $O$ primeiro recorte ilustrativo versa sobre a influência do modelo de acumulação flexível no processo de saúde/doença em trabalhadores com diagnóstico de Lesões por Esforços Repetitivos/Distúrbios Osteomusculares Relacionados ao Trabalho. Um segundo recorte ilustrativo analisa a implantação do modo de gestão da Qualidade Total, preconizado pelo modelo de acumulação flexível em um órgão público do poder judiciário. Por último, examina-se a trajetória das mutações da função de telefonista/teleoperador, considerando-se os "call-centers" como ícones representativos das transformações do trabalho na contemporaneidade. Esses recortes são examinados priorizando as implicações e expressões no processo de saúde/doença mental e seus vínculos como trabalho com base em fundamentos da psicologia social.

Palavras-chaves: Trabalho; processo saúde/doença; trabalho e subjetividade.

\footnotetext{
"Work on contemporaneity and its implications on workers' subjectivity

'Endereço para correspondências: Rua São Manoel, 1970/403, Porto Alegre, RS, 90620-110 (silvana_deoliveira@hotmail.com).

${ }^{2}$ Trabalho apresentado em mesa-redonda no XII Encontro Nacional da Associação Brasileira de Psicologia Social/ABRAPSO, Porto Alegre, outubro de 2003. Os comentários da Prof Leny Sato (USP) quando da realização da mesa-rednda foram incorporados ao texto nos comentários e considerações finais.
} 


\title{
HUMANAS
}

\begin{abstract}
The aim of this theoretical essay is to analyse the changes in course on world of work and its implications on workers' subjectivity. Based on three illustrative cases, we analyse the implications which are expressed on workers' ways of living and getting sick. The first illustrative case is about the influence of flexible accumulation model on health/illness process in workers with diagnostic of Repetitive Strain Injuries / Work-Related Musculoskeletal Disorders. A second illustrative case analyse the implementation of Total Quality management, recommended by the flexible accumulation model on a judiciary public institution. Finally, we examine the mutations on telephone operator function, considering the call centers as representative icons of work transformations on contemporaneity. These cases are analysed favoring implications and expressions on mental health/illness process and its relations with work based on social psychology foundations.
\end{abstract}

Keywords: Work; heatlh/illness process; work and subjectivity.

\section{1 - Introdução}

$\mathrm{N}$ as últimas décadas se introduziram complexas mudanças nos contextos de trabalho em um ritmo acelerado. No caso particular do setor produtivo brasileiro, constata-se a coexistência de diferentes estágios de incorporação tecnológica, diversas formas de organização e gestão, relações e contratos de trabalhos variados que se expressam em modos também variados de trabalhar e de viver, de adoecer e de morrer dos trabalhadores.

O tema trabalho é recorrente na trajetória histórica da psicologia desde seus primórdios como disciplina científica. Nos primeiros anos do século $\mathrm{XX}$, sua principal demanda era atender aos interesses do setor industrial em expansão, desenvolvendo medidas psicológicas de avaliação das diferenças individuais, na busca "do homem certo para o lugar certo".

A partir da década de 30, a conjuntura econômica e social redirecionou as contribuições da psicologia, especialmente da psicologia social, para questões referentes à motivação e à satisfação no trabalho. Ganham relevância os estudos sobre clima e cultura organizacionais, a análise dos fatores psíquicos na produtividade dos trabalhadores e a prática psicológica aplicada ao contexto laboral apregoando o equilíbrio, a harmonia e a cooperação. 
O trabalho na contemporaneidade e suas implicações na subjetividade dos trabalhadores Adriana Spilki, Maria da Graça Jacques, Miriam Scopel e Silvana de Oliveira

Mesmo com a valorização do conflito no processo de crescimento e desenvolvimento organizacionais, a ênfase recaía no emprego de estratégias psicológicas de identificação desses conflitos e sua canalização para a eficiência do sistema.

O tratamento conferido ao tema trabalho pela psicologia foi objeto de censura de autores renomados como Marx e Fromm. Marx (1989) criticava a psicologia do século XIX e perguntava o que se poderia dizer de uma ciência que, orgulhosamente, abstraia o trabalho humano real e concreto, a não ser que se tratava de uma ciência incompleta e desprovida de conteúdo e realidade. Fromm alertava sobre as formas de aplicação do conhecimento psicológico que incrementavam "o empresário de utilidades sem comprometer-se com a situação do trabalhador" (FROMM, 1956, p. 269).

Críticas semelhantes partem de autores que examinam a trajetória da psicologia no Brasil (por exemplo, CODO, 1985 e SPINK, 1996). Mesmo considerando a advertência de que esse não é um privilégio da psicologia, pois os conhecimentos científicos, em geral, são apropriados pelos modos de produção para se manterem e se multiplicarem, importante se faz incluir a contribuição da psicologia, e da psicologia social em particular, que represente uma ruptura com esse tratamento hegemônico conferido ao tema trabalho.

O objetivo desse artigo é examinar as transformações ora em curso no mundo do trabalho e suas implicações na subjetividade dos trabalhadores, a partir de uma perspectiva da psicologia social em que a subjetividade é compreendida como vinculada aos processos sociais e históricos. Procura-se romper a tendência de uma psicologia implicada com a administração de recursos humanos em que seus conhecimentos são empregados tão somente buscando a adaptação dos trabalhadores e o aumento da produtividade. A partir de três recortes ilustrativos, analisa-se as implicações daí derivadas que se expressam nos modos de ser, de viver e de adoecer mentalmente dos trabalhadores.

$O$ primeiro recorte ilustrativo versa sobre a influência do modelo de acumulação flexível no processo de saúde/doença dos trabalhadores, especificamente em trabalhadores com diagnóstico de LER/DORT (Lesões por Esforços Repetitivos/ Distúrbios Osteomusculares Relacionados ao Trabalho). Essa síndrome tem tido uma freqüência elevada de incidência em trabalhadores em todo o mundo e, no Brasil, segundo o Manual de Procedimentos para os Serviços de Saúde do Ministério da Saúde (BRASIL, 2001) responde por mais de $80 \%$ dos diagnósticos que resultaram em concessão de auxílio-acidente e aposentadoria por invalidez pela Previdência Social. 


\section{HÜMANAS}

Um segundo recorte ilustrativo examina a implantação da gestão da Qualidade Total, como modo de gestão preconizado pelo modelo de acumulação flexível, disseminada em empresas públicas e privadas e suas implicações nos trabalhadores. A partir de uma análise de sua implementação em um órgão público do poder judiciário, aborda-se como essa lógica se expressa no discurso da eficácia do poder judiciário e na avaliação da qualidade do trabalho dos servidores.

Por último, acompanha-se a trajetória das mutações da função de telefonista/teleoperador, as estratégias de enfrentamento utilizadas e as implicações daí derivadas no processo de saúde/doença mental dessa categoria funcional. A escolha se fez visto que as operações dos chamados "call-centers" são ícones representativos das transformações do trabalho na contemporaneidade.

Esses recortes são examinados com base nas contribuições da psicologia social a partir de uma perspectiva que prioriza as implicações sobre os trabalhadores e suas expressões no processo de saúde/doença mental.

O impacto do sofrimento e adoecimento através do trabalho pode ser analisado por diferentes indicadores e causado por sistemas complexos de relações e condições laborais. Chanlat (1995) aponta para a relação entre os modos de gestão e o processo de saúde-doença dos trabalhadores, destacando que a gestão da saúde depende da gestão do trabalho e que esse processo se faz notar em dois níveis: nos níveis de segurança, a respeito dos pequenos incidentes que apontam a adaptação da organização dos trabalhadores e, em nível de saúde, a partir dos indicadores de patologias e os tipos mais prevalentes.

No entanto, quando se adentra o campo da saúde em seus vínculos com o trabalho, necessário se faz ultrapassar os conceitos "negativos" que definiam a saúde pela ausência de doença e compreender a historicidade dos processos biológicos e psíquicos humanos. Segundo Laurell e Noriega (1989), a biologia humana não é a-histórica e os processos biológicos se dão em grupo que têm uma inserção social específica. Para os autores, o trabalho enquanto atividade especificamente humana, consciente, orientada para um fim é a base da criatividade, por suas qualidades deve ser destacado na compreensão da relação humana com a natureza e das condições de produção de saúde.

Outros enfoques de análise são possíveis e se pretende suscitar esse debate. 
O trabalho na contemporaneidade e suas implicações na subjetividade dos trabalhadores Adriana Spilki, Maria da Graça Jacques, Miriam Scopel e Silvana de Oliveira

\section{2 - O modelo de acumulação flexível e suas implicações na ocorrência de LER/DORT.}

Cada sociedade, conforme o momento histórico, o contexto político, social, econômico e cultural, apresenta seus códigos e dispositivos através dos quais os indivíduos balizam sua conduta, No campo do trabalho, constatam-se modificações nesses códigos e dispositivos decorrentes da passagem do modelo taylorista-fordista para o da acumulação flexível, cada qual conformando uma determinada ética do trabalho. O modelo taylorista-fordista se sustentou através do princípio do "Pacto Social" em torno do tripé Estado/ Capital/ Trabalho, no qual a promessa do pleno emprego e a regulamentação do trabalho, garantiriam a distribuição de renda e o crescimento econômico.

No modelo taylorista-fordista de gestão, o trabalho se pautava no controle dos tempos e movimentos, em atividades repetitivas e simples, de forma que o trabalhador tivesse "alto" rendimento através da reprodução mecânica e com menor desperdício de tempo. O planejamento do trabalho era separado e independente da área de execução.

No modelo de acumulação flexível que se dá no contexto da globalização, no qual a informática e o desenvolvimento das redes interligadas de comunicação têm papel fundamental, novas formas de trabalho se estabelecem. Modificam-se as formas de gestão que vão constituir-se em dispositivos que alteram profundamente os processos de subjetivação dos trabalhadores (NARDI, 2003).

Assiste-se a uma exacerbação do individualismo, estímulo à competitividade entre os pares e um código mais restritivo em que a contribuição dos trabalhadores interessa na medida em que haja uma incorporação das metas e objetivos da empresa. O que sustenta o modelo é a ameaça do desemprego, o sentimento de insegurança em relação ao futuro e a falta da perspectiva de busca de uma saída coletiva acirrada pelo descrédito da ação sindical.

Essas transformações impuseram novos modos de adoecimento dos trabalhadores e/ou novos modos de manifestação de patologias associadas ao trabalho como a LER/DORT. LER/DORT é descrita pelo INSS (Ordem de Serviço/ INSS n ${ }^{\circ}$ 606/1998) como uma síndrome clínica, caracterizada por dor crônica, acompanhada ou não por alterações objetivas, 
que se manifesta principalmente no pescoço, região escapular e/ou membros superiores em decorrência do trabalho. Assim, são espécies de LER/ DORT as neuropatias compressivas ${ }^{3}$, como a "síndrome do desfiladeiro toráxico" e a "síndrome do túnel do carpo"; as tendinites, epicondilites e tenossinovites ${ }^{4}$, as fibromialgias e assemelhadas. ${ }^{5}$

Além das limitações físicas que interferem na capacidade laboral e funcional dos trabalhadores lesionados, a literatura (por exemplo, SATO, 2003) refere as repercussões psicossociais decorrentes, como a presença de sentimentos de culpa e de comportamentos depressivos advindos de dúvidas, incertezas, humilhações e preconceitos a que se submetem, além das limitações físicas e da presença da dor crônica.

No modelo taylorista-fordista o crescimento dos casos de LER/DORT se deu a partir do exercício de tarefas repetitivas em ritmo intenso determinado pela linha de montagem. A lógica do modelo de acumulação flexível impõe um ritmo acelerado de produção, uma responsabilização individual do trabalhador pela sobrevivência da empresa e na empresa e controles sofisticados de produtividade. Além disso, sob o ponto de vista clínico, dificultamse o retorno ao trabalho e a reinserção social desses trabalhadores.

Diretamente implicado no processo de adoecimento está a submissão desses trabalhadores a esse regime de verdades; com relação aos casos de LER/DORT, dentro de uma organização de trabalho patogênica, os trabalhadores mais responsáveis, exigentes, perfeccionistas, que tentam atingir ou ultrapassar as metas de produtividade impostas pela empresa, estão mais expostos ao adoecimento. Lima (1998), ao comparar um grupo de bancários lesionados com um grupo de não lesionados do mesmo setor, reconhece nesses últimos uma postura "mais flexível em relação ao atendimento de exigências, tentando entender melhor seus limites e estabelecer uma distância mínima em relação à instituição onde trabalham de modo a preservar um pouco sua vida pessoal" (LIMA, 1998 p. 105).

Pode-se concluir que os trabalhadores lesionados mais se sujeitam ao regime de verdades que impõe condições patogênicas de trabalho. Além disso, a competitividade entre colegas, a ameaça de desemprego e a necessidade de luta pela sobrevivência restringiram de forma acentuada as práticas de resistência que poderiam transformar as condições laborais a que estão submetidos.

\footnotetext{
${ }^{3}$ Doenças causadas por compressão dos nervos pelos ossos ou músculos

4 Inflamações nos tendðes ou nas bainhas tendíneas (estrutura fibrosa que liga o tendão no osso)

${ }^{5}$ Como a síndrome de fadiga crônica. Essas últimas espécies são de mais difícil caracterização como DORT porque não são localizadas como as demais lesões.
} 
Os referenciais da psicologia social subsidiam as explicações dos novos modos de subjetivação dos trabalhadores no contexto atual do mundo do trabalho. As implicações da passagem de uma situação de relativa segurança de direitos adquiridos para um estado de insegurança e falta de referências para lidar com as transformações introduzidas no contexto laboral, a exacerbação do individualismo, a perda da crença nas formas coletivas de resistência e o consumismo que rege a vida em sociedade deixam uma sensação de desesperança e reforçam comportamentos de submissão que se expressam em novos modos de adoecimento de antigas doenças relacionadas ao trabalho. No Brasil, convivem várias formas de organização do trabalho, desde o modelo taylorista-fordista até o modelo de acumulação flexível, passando pelas formas precarizadas de trabalho como o trabalho escravo, por exemplo, que se refletem nas estatísticas dos casos de LER/DORT, a partir de processos e causas diversas de adoecimento.

Todas essas características se expressam e são difundidas através dos novos modelos de gestão de pessoal implementados nas organizações, como é o caso do modelo da Qualidade Total.

\section{3 - A gestão da Qualidade Total em órgãos públicos: implicações nas formas de trabalhar dos servidores.}

Entende-se por modo de gestão o conjunto de procedimentos administrativos determinados pela direção da empresa para atingir as metas estabelecidas (CHANLAT, 1996). Segundo o autor, os modos de gestão podem ser classificados como taylorismo e neotaylorismo, tecno-burocrático, baseado na excelência ou Qualidade Total e participativo. Afirma que o modo de gestão da Qualidade Total, que denomina de "Gestão da Excelência", baseia-se na idéia de produzir melhor que os concorrentes, enfatizando "o primado do êxito, a supervalorização da ação, a obrigação de ser forte, a adaptabilidade permanente, a canalização da energia individual nas atividades coletivas, o desafio permanente" (CHANLAT, 1996, p. 121).

Paladini (1994) afirma que a principal missão das organizações na visão da Qualidade Total é a satisfação plena do cliente e a "existência da empresa é justificada pelo produto, método ou serviço que ela fornece à comunidade, independente de sua natureza ou utilidade" (PALADINI, 1994, p. 25). 


\title{
HUMANAS
}

Barros (1993) afirma que a gestão pela Qualidade Total pode ser usada de forma a dificultar e, até mesmo, inviabilizar estratégias coletivas de organização do trabalho já que, nesse método de gestão, existe a busca por homogeneidade de objetivos e ações. Salienta, ainda, a importância do conceito da sobre-implicação para essa forma de gestão:

\begin{abstract}
A sobre-implicação é a exigência não mais apenas de um corpo docilizado, mas de uma subjetividade socializada ansiando por mais identificação com as organizações e instituições que lhe exigem um suplemento de valor. A sobre-implicação é o regime no qual a Qualidade Total conforma o dispositivo-grupo como aliado em seu projeto de instalar um 'nós' que vem carregado de uma pausterização que homologa o modoindivíduo(BARROS, 1993, p.190-1).
\end{abstract}

Wood Jr. e Urdan (1994) apontam a implementação da gestão da Qualidade Total nos serviços públicos a partir de demandas como aumento da produtividade, envolvimento do usuário, atribuição de maior poder decisório aos funcionários, necessidade de medir e divulgar o desempenho e desenvolver planos estratégicos de longo prazo. No entanto, apontam para a necessária adaptação às circunstâncias do contexto governamental.

Tal modelo, implementado nos órgãos públicos, tem produzido efeitos na subjetividade dos trabalhadores que passam a exercer suas atividades em regime típico das organizaçðes empresariais. Conforme Deleuze (1990), na sociedade de controle tudo é transformado na lógica da empresa e, nesse tudo, pode-se incluir os órgãos e a administração pública.

Como exemplo de implementação de programas de Qualidade Total em órgãos públicos, está a implantação do programa dos " $5 \mathrm{~S}$ " em um serviço da instância judiciária. Tal implantação foi precedida da criação de um setor denominado "Escritório da Qualidade", seguido de palestras sobre motivação, liderança, competitividade e importância do lucro.

Oprograma foi instituído a partir de um folheto explicativo que define assim o programa: "os $5 \mathrm{~S}$ são 5 palavras-chave de origem japonesa que, colocadas em prática conseguem, como num toque de mágica, transformar os locais de trabalho em ambientes cada vez mais agradáveis, seguros e produtivos. 
O trabalho na contemporaneidade e suas implicações na subjetividade dos trabalhadores Adriana Spilki, Maria da Graça Jacques, Miriam Scopel e Silvana de Oliveira

É um programa de consciência individual, mas que precisa da participação de todos para se tornar realidade".

Segundo Binotto (2002), a "filosofia" dos $5 \mathrm{~S}$ tem forte abordagem motivacional, e teria sido um fatores para a recuperação das empresas japonesas e foi a base dos programas de qualidade total. Parte da crença que "as pessoas que freqüentam um ambiente agradável, saudável e em constante aperfeiçoamento tendem a evoluir em seus hábitos e atitudes". O nome das palavras japonesas, adaptadas ao Brasil são: senso de utilização (seiri), senso de ordenação (seiton), senso de limpeza (seison), senso de saúde-bemestar (seiktsu) e senso de autodisciplina (shitsuke).

Outros trechos desse material explicativo retratam o conceito de sobre-implicação desenvolvido por Barros (1993)

[...] os conceitos transmitidos pelos "5 S" são
coerentes como o nosso jeito de ser. Aprenda,
pratique e compartilhe o seu conhecimento. A
autodisciplina requer constante aperfeiçoamen-
to; se está bom pode ficar ainda melhor! (...)
Superar nossos limites é gratificante e desafi-
ador(...). (BARROS, 1993, p.190-1).

Tais argumentações se sustentam em características das empresas capitalistas como a competitividade e o individualismo. Volnovich (1996, p. 63), ao dissertar sobre a subjetividade nas organizações, ressalta que "as metáforas sociais e as metáforas psíquicas não funcionam em paralelo, pelo contrário, estão profundamente entrelaçadas". Conclui que a subjetividade se constitui através de uma economia subjetiva de pequenos gozos narcísicos em que a individualidade se contrapõe ao coletivo.

No caso da instância judiciária, a implantação da gestão da Qualidade Total apresenta-se como uma solução para a atual sobrecarga de trabalho. Obscurece fatores relevantes como a desqualificação de pessoal devido à ausência de concursos públicos para suprir a carência, contratação de "estagiários" e envolvimento direto dos servidores na redução e/ou solução dos casos. A prática de concessões de Funções Gratificadas (FGs) e Cargos em Comissão (CCs) corrobora com os princípios defendidos pela gestão da Qualidade Total, ensejando a competitividade e instabilidade dos servidores, responsabilizando-os pela perda de função e menor remuneração. 
A utilização desses mecanismos corrobora para a incidência das LER/DORT no setor judiciário, estimulando comportamentos compatíveis com a perspectiva da acumulação flexível em que os trabalhadores mais comprometidos com a lógica do sistema se tornam mais susceptíveis ao adoecimento.

Embora pensar na gestão da Qualidade Total em órgãos públicos seja de importância na compreensão das transformações ora em curso nas relações de trabalho, é possível ampliar as reflexões para a constituição de sujeitos da Qualidade Total enquanto campo de análise da psicologia social. Os sujeitos da Qualidade Total não estão restritos a empresas privadas ou órgãos públicos mas se disseminam nos mais diversos âmbitos da vida contemporânea.

Em algumas categorias profissionais, as transformações introduzidas no mundo do trabalho determinaram profundas alterações no modo de trabalhar e no perfil dos trabalhadores. Um exemplo ilustrativo é a criação da categoria funcional de teleoperadores.

\section{4 - De telefonistas a teleoperadores: novos modos de trabalhar e de subjetivação.}

As telecomunicações foram um dos campos de trabalho que mais sofreram modificações com o advento de novas tecnologias. Influenciaram e foram influenciadas significativamente pelas mudanças econômico-sociais dos últimos cinqüenta anos no Brasil, e no contexto de globalização do capital. São processos que geraram novas formas de trabalhar e de subjetivação. Movimentos decorrentes dessas transformações no campo de trabalho se expressam nas formas que o trabalho de telefonista tomou. São regularidades e rupturas nas configurações dessa área profissional que se apresentam como um conjunto de composições de força e de políticas e verdades.

A categoria profissional de telefonista foi uma das pioneiras como campo de pesquisa nos estudos sobre saúde e trabalho (JULLIARD, 1910, citado por LE GUILLANT et al.) e sobre saúde mental e trabalho. Caracterizava-se como um trabalho penoso, com muitos acidentes de descargas elétricas e com grande ruído que causava perdas de audição; as supervisões eram ostensivas, o trabalho repetitivo e com forte exigência de produtividade, utilização de escutas para controle dos scripts de fala e padrão de atendimento.

Segundo Pacheco (2002), até 1984, as companhias telefônicas necessitavam de pessoas com poucas possibilidades de crescimento profissional, que se acomodassem na função e que permanecessem na atividade por muitos anos. 


\section{O trabalho na contemporaneidade e suas implicações na subjetividade dos trabalhadores}

Adriana Spilki, Maria da Graça Jacques, Miriam Scopel e Silvana de Oliveira

Era comum mulheres se aposentarem como telefonistas. Coloca que:

[...] para garantir a estabilidade dos trabalhadores no cargo, uma vez que, o tempo na função era um dos fatores que permitia o conhecimento do processo de trabalho e o domínio das habilidades relacionais, até 1984 , a [X \} selecionava telefonistas exclusivamente do sexo feminino, com formação máxima de primeiro grau - sempre indicadas por outras colegas telefonistas - que, em geral, eram moças de famílias pobres, solteiras e sem muitas possibilidades de ascensão social. (PACHECO, 2002, p. 114).

Pondera que era esperado que a telefonista se mostrasse paciente, gentil e atenciosa nos atendimentos. Os homens não eram contratados, pois eram considerados impacientes, grosseiros, pouco afetivos, menos submissos e mais ambiciosos do que as mulheres. A gênese das LER/DORT entre telefonistas se inscrevia em um contexto atravessado pela categoria gênero, em que o discurso era de que se tratava de uma patologia de mulheres, por serem mais fracas e histéricas, entre outros fatores.

A partir da década de 80 do século XX, introduziram-se importantes inovações tecnológicas na telefonia como o Distribuidor Automático de Chamadas, o Medidor Automático de Rapidez de Atendimento e o Sistema Eliminador de Bilhetes Interurbanos. Tais inovações acarretaram modificações no processo de trabalho e nos mecanismos de controle das operações.

A questão do tempo passou a ser central em todas as dimensões do trabalho de telefonista. Embora diga seu nome ao receber a chamada ou ao se apresentar, o que era proibido até a década de 80 , a prescrição rígida da fraseologia a ser empregada empobrece a relação com o cliente. Além disso, são implementados modos sofisticados de escuta e mecanismos individualizados de controle da produtividade, pautados nos princípios da acumulação flexível: competitividade entre os pares, insegurança no emprego, responsabilização individual pela permanência da empresa e na empresa...

Altera-se o perfil dos trabalhadores recrutados: exigência de maior escolaridade, de conhecimentos técnicos de informática, digitação veloz e uso rígido da fraseologia. Segue a demanda por cordialidade, cortesia, paciência, bem como "voz adequada", sendo admissíveis homens com tais qualidades consideradas femininas. 


\section{HUMANAS}

A mudança do nome da categoria funcional de telefonista para teleoperador, atendente de serviço, atendente de cadastro, entre outras, com a justificativa de remediar a entrada de trabalhadores homens, acarretou a perda de uma série de garantias legais trabalhistas da categoria e uma confusão sobre a identidade sindical desses trabalhadores. Além disso, pesquisas recentes revelam um alto índice de rotatividade desses trabalhadores. Assunção e Vilela (2002, p. 25) registram um percentual de $96 \%$ de rotatividade em cada dois anos, e uma média, segundo Peres $(2003$, p. 98) de 13,6 meses de permanência nas empresas.

Esse contexto de mutação na atividade de telefonista está constitutivamente implicado com as transformações da subjetividade dos trabalhadores na contemporaneidade. As novas verdades advindas da tecnologia, o ideal de "atendimento personalizado de massas", as demandas do mercado e as estratégias das sociedades de controle sobre o corpo disciplinado compuseram esse híbrido controle-disciplina que é o teleatendimento. Outros regimes de força se configuram bem como continuidades que seguem desde um período anterior.

O modelo de acumulação flexível ao modo de gestão da Qualidade Total são prioritariamente escolhidos como modelos em empresas de teleatendimento, em geral, empresas terceirizadas que prestam serviços a empresas telefônicas e trabalhos de telemarketing para outras empresas. A ocorrência de casos de LER/DORT nessas empresas tem um percurso semelhante a de empresas com modelo de acumulação flexível, mas estão encobertos pela elevada rotatividade de pessoal.

\section{5 - Comentários e considerações finais}

A trajetória da psicologia restringiu e empobreceu a análise da relação homem - trabalho. Na psicologia social, muitos dos estudos e pesquisas desenvolvidos estavam mais voltados a questões relacionadas com a produtividade e com a adaptação dos trabalhadores ao contexto laboral.

Os três recortes ilustrativos apresentados neste ensaio teórico ensejam uma reflexão sobre a gestão do trabalho e as consequiências para os trabalhadores e ajudam a angariar argumentos que possibilitam configurar a categoria trabalho como objeto nobre da psicologia, ressignificando o campo da chamada psicologia do trabalho e das organizações/ instituições, concedendo-lhe o mesmo grau de importância de outras áreas da psicologia. 
O trabalho na contemporaneidade e suas implicações na subjetividade dos trabalhadores Adriana Spilki, Maria da Graça Jacques, Miriam Scopel e Silvana de Oliveira

Tal ressignificação se tem presenciado, no Brasil, nos últimos anos e essa mudança de foco tem muito a ganhar com a leitura da psicologia social que possibilita pensar as pessoas em relação, as pessoas em interação e em contexto.

O modelo de acumulação flexível é ilustrativo de novas formas de adoecimento dos trabalhadores ou de novos caminhos de velhas doenças como as LER/DORT. Constitui-se em mais um modelo adotado pelo contexto brasileiro em que formas antigas e novas convivem lado a lado.

Tal modelo problematiza a questão da reinserção profissional de portadores de LER/DORT, pois voltar ao trabalho é voltar dentro de uma condição de trabalho patogênica, em meio a insegurança sobre a possibilidade de respeitar os limites subjetivos e em meio a uma verdade construída de que o adoecimento se deve a uma fraqueza individual. Voltar ao trabalho não é voltar o mesmo, pois, em primeiro lugar, em termos físicos e psicológicos ocorreram mudanças decorrentes do acometimento por LER/DORT. Em segundo lugar, porque essas pessoas foram obrigadas a refletir sobre esse acontecimento o que, talvez, as tenha levado a ressignificar o trabalho nas suas vidas; enfim, um olhar menos ingênuo para o mundo do trabalho.

Em geral, os estudos críticos nas ciências sociais (incluindo-se aqui a psicologia) se voltaram a trabalhadores industriais e, posteriormente aos de serviços. O caso da implementação da gestão da Qualidade Total na instância judiciária aponta para a visibilidade de seu quadro funcional enquanto trabalhadores e as implicações daí decorrentes. Coloca-se, ainda, a questão de como as condições/ organização de trabalho e formas de gestão, de um modo geral, repercutem na possibilidade de alcançar um serviço que sirva ao interesse do bem público.

O trabalho de reconstituição histórica de uma categoria profissional telefonistas - apontando as continuidades e rupturas nas formas de organização do trabalho e no conteúdo das tarefas, entremeadas pela disponibilização de novas tecnologias e novas ofertas de serviços à população, mostra-se um caso "sentinela" para avaliar as transformações ora em curso. Ao reler o trabalho clássico de Le Guillant e colaboradores (1984), de 1936, sobre as neuroses das telefonistas, constata-se a manutenção de um padrão de queixas, de adoecimento e controles gerenciais há mais de 50 anos. Um dirigente sindical se referia, certa vez, a preferência das empresas de "call center" em selecionar trabalhadores negros em função de seu timbre de voz, uma das características em termos de atributos pessoais que conformam a categoria dos trabalhadores telefônicos. 
Os três recortes ilustrativos focam a dimensão dos processos de subjetivação em contextos distintos de trabalho, cada um deles elegendo categorias profissionais distintas e focos também distintos. Expressam o crescimento significativo de estudos empíricos com referenciais da psicologia social que toma o trabalho e as organizações/instituições como objeto. É a partir da análise desses recortes que se pode buscar respostas acerca da multiplicidade de possibilidades e de constrangimentos para uma construção individual e coletiva determinada e limitada pela estrutura social.

\section{Referências bibliográficas}

ASSUNÇÃO, A; VILELA, L. As condições de adoecimento na empresa. CONTAX: estudo ergonômico. Belo Horizonte: Ministério Público do Trabalho/Faculdade de Medicina da UFMG 2002.

BARROS, B. R. Grupos e produção. In BAREMBLITT, G. (org.) Saúde e loucura: grupos e coletivos. São Paulo: Hucitec, 1993, p. 145-154.

BINOTTO, V.A comunicação interna na gestão da qualidade total - um diagnóstico da comunicação interna do programa pela gestão da qualidade total do Hospital de Guarnição de Santa Maria. In: Congresso Brasileiro de Ciências da Comunicação, 25, 2002, Salvador. Anais. São Paulo: Intercom, 2002. C-ROM

CHANLAT, J.F. Modos de gestão, saúde e segurança no trabalho. In: DAVEL, E. F, VASCONCELOS, J. (orgs.). "Recursos" humanos e subjetividade. Petrópolis: Vozes, 1996, p. 118-128

CODO, W. O papel do psicólogo na organização industrial (notas sobre o "lobo mau" em psicologia). In: LANE, S. e CODO, W. (orgs.) Psicologia social: o homem em movimento. São Paulo: Brasiliense, 1985, p. 195-202

DELEUZE, G. Conversações. Rio de Janeiro: Editora 34, 1990

FROMM, E. Psicoanálisis de la sociedad contemporánea. México: FCE, 1956

LE GUILLANT, L. A neurose das telefonistas. Revista Brasileira de Saúde Ocupacional, n. 47, v. 12, p. 7-11, 1984.

LIMA, M.E. A LER no setor bancário. In: GARCIA DE ARAÚJO, J.N.; LIMA,F.P.A. e LIMA,M.E.A.(org.) L.E.R.: Dimensões ergonômicas e psicossociais. Belo Horizonte: Livraria e Editora Saúde,1998, p. 52-107 
MARX, K.O capital. (13 ed.). São Paulo: Bertrand Brasil, 1989

BRASIL. MINISTÉRIO DA SAÚDE. Doenças relacionadas ao trabalho; manual de procedimentos para os serviços de saúde. Brasília: Ministério da Saúde, 2001.

NARDI, H. Trabalho e Ética: os processos de subjetivação de duas gerações de trabalhadores metalúrgicos e do setor informal (1970-1999).Tese de Doutorado em Sociologia. Porto Alegre, Programa de Pós Graduação em Sociologia, Instituto de Filosofia e Ciências Humanas, UFRGS, 2002

PACHECO, V. Gênero, saúde e trabalho: fatores que interagem no desenvolvimento de LER em trabalhadores telefônicos. Dissertação de mestrado, Faculdade de Filosofia e Ciências Humanas, Universidade Federal de Minas Gerais, 2002

PALADINI, E. Qualidade Total na prática: implantação e avaliação de sistemas de qualidade total. São Paulo: Atlas, 1994

PERES, C. Satisfação com o sistema de pausas no trabalho em teleatendimento/telemarketing. Dissertação de Mestrado, Escola de Engenharia, Universidade Federal do Rio Grande do Sul, 2003

SATO, L. Subjetividade, saúde mental e LER. In: RUIZR. (Org.). Um mundo sem LER é possível. Montivedéu: Rel-UITA, 2003, p. 61-80

SPINK, P. Organização como fenômeno psicossocial: notas para uma definição da psicologia do trabalho. Psicologia e Sociedade, n. 8, v. 1, p. 174-192, 1996

VOLVONICH, J. Subjetividade e organizações: o discurso neoliberal. In: DAVEL, E. F, VASCONCELOS, J. (orgs.). "Recursos" humanos e subjetividade. Petrópolis: Vozes, 1996, p 61-67

WOOD JR. T., URDAN, F. Gerenciamento da Qualidade Total: uma revisão crítica. Revista de Administração de Empresas, n. 34, v. 6, p. 46-59, 1994. 